\title{
HDL-Cholesterol Subclass 2 Measurement
}

National Cancer Institute

\section{Source}

National Cancer Institute. HDL-Cholesterol Subclass 2 Measurement. NCI Thesaurus. Code C80187.

The determination of the amount of HDL-cholesterol subclass 2 present in a sample. 